\title{
Dora
}

\section{Ignacio MinaverRy}

La Editorial Común / La Maroma Editores, 2009-2018

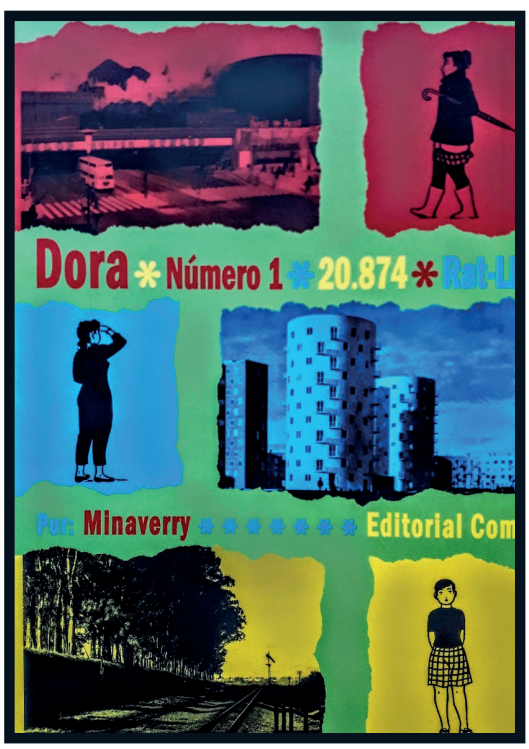

\section{DORA: ¿ESPÍA O TRABAJADORA DEL ARCHIVO?}

$\mathrm{H}$ asta la fecha, Ignacio Minaverry ha publicado cuatro libros que constituyen la saga que sigue las vivencias de Dora Bardavid y sus amistades en los años posteriores a la Segunda Guerra Mundial. Las historias que se desprenden de las búsquedas y luchas de Dora y el resto de los personajes nos llevan por países de Europa, específicamente Alemania y Francia, y Argentina. Minaverry trae a las viñetas su propia perspectiva sobre la posguerra; las luchas y búsqueda por justicia, que tiene más que ver con las luchas cotidianas de personajes entrañables y cercanos, que con persecuciones o enfrentamientos con villanos. Asimismo, el historietista argentino logra con sus enigmáticos trazos y tramas en blanco y negro, ilustrar estas historias, elaborando varias alusiones al momento histórico, la arquitectura y sus elementos representativos.

El primer número Dora: Rat-line (1959-1962), publicado en el 2009, se inicia en Alemania, mientras Dora empieza un trabajo fichando documentos para el Berlin Document Center impulsada por su deseo de comprender qué le sucedió a su padre tras ser detenido y llevado a un campo de concentración; es decir, entender su historia familiar. Nos enteramos que su madre le puso su nombre por el campo de concentración Dora Mittelbau, sitio que ahora es un museo de la memoria, donde su padre murió. Esto subraya el profundo vínculo de ese trauma familiar en el presente de este personaje, ya que Dora busca encontrar la verdad de lo que le sucedió a su padre, pero en el trayecto se está buscando a sí misma también.

Ahora, sin embargo, nos interesa la presencia del archivo en estas historietas de $\mathrm{Mi}$ naverry, y principalmente cómo el trabajo sobre estos archivos por parte de Dora la convierten en una espía e investigadora con una impronta poco tradicional. En las vi- 


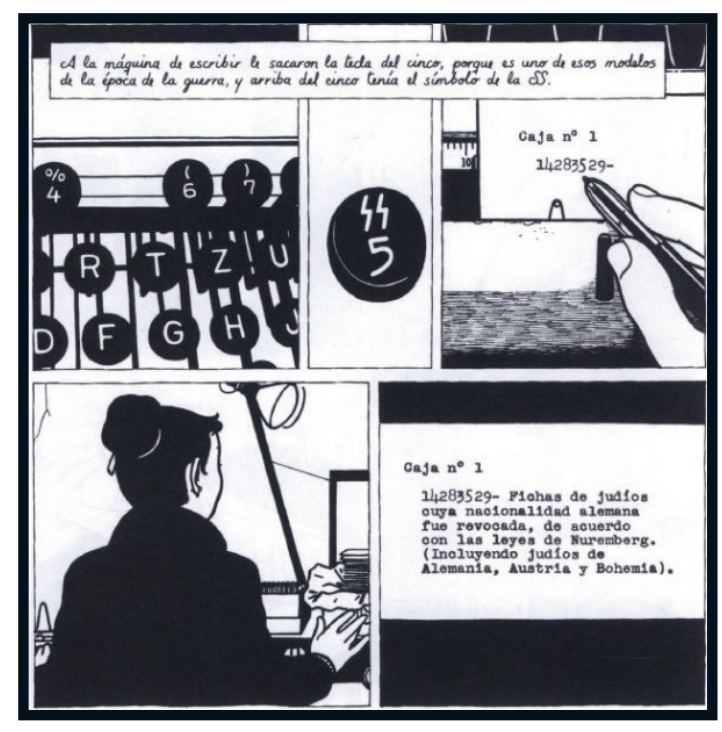

FIG. 1. Dora: Rat-line (1959-1962)

(La Editorial Común, 2009), s.p.

ñetas de la FIG. 1 se muestra a Dora en el comienzo de su trabajo, fichando los documentos de la burocracia del régimen nazi. Como revela la tecla extirpada con el símbolo de las SS, la máquina de escribir y Alemania exhiben la huella de ese pasado que Dora vislumbra cuando descubre que su jefe tiene un pasado militar nazi y, aun así, se encuentra a cargo de documentos tan sensibles y fuera del radar de la justicia. A partir de esto y de su trabajo incansable con los documentos que poco a poco va sistematizando, ordenando y fichando, ella reconoce este como su archivo. Así pues, comienza a hacer copias de los archivos con una cámara que contrabandea en su trabajo, de forma que se apropia del archivo de manera definitiva, y se autodenomina, por primera vez, «espía».

Dora deviene guardiana del archivo, es decir, arconte con poder de consignación, en términos que utiliza Derrida en Mal de archivo para definir a quienes: «no solo aseguran la seguridad física del depósito y del soporte, sino que también se les concede el derecho y la competencia hermenéuticos. Tienen el poder de interpretar los archivos». ${ }^{1}$ Este poder de consignación, por lo tanto de reunión y articulación del archivo, como aclara Derrida, se manifiesta en la información que le llega a partir del momento que empieza su labor arcóntica: su amiga Judith le escribe que sospecha haber visto a Mengele en un pueblo argentino bajo el alias de Otto Graf.

En este momento, Dora es abordada por Lucien, un agente del Mossad, que le encarga tareas de espionaje. Entonces viaja a Argentina para espiar a quien puede ser el prófugo médico nazi más buscado de la posguerra. Ahora bien, Dora no cae dentro de los parámetros de lo que esperamos de un espía en la tradición de las historietas. Tomemos como punta comparativa la figura de Steve Canyon (1947) o Spy Fighters (1951), para acercarnos a la construcción del héroe de las historietas de espías estadounidenses. Según D. R. Hammontree en «Espionage», dentro de Comics through Time: A History of Icons, Idols and Ideas: «Spy Fighters featured federal agent Clark Mason, whose cases were advertised as being "torn from actual official records"», ${ }^{2}$ estableciendo así un vínculo con supuestos documentos reales del conflicto de la Guerra

\footnotetext{
${ }^{1}$ Derrida, J. Mal de archivo. Una impresión freudiana. Madrid, Trotta, 1997, p. 3.

${ }^{2}$ Hammontree, D. «Espionage», en Keith Booker, M. (ed.). Comics through Time: A History of Icons, Idols and Ideas. Greenwood Press, 2014, p. 126.
} 
Fría. El espía en estas viñetas se configuraba como un héroe patriota, hombre blanco heterosexual, paradigma de la norma patriarcal, que domina el combate y tácticas de contrainteligencia. Mientras que la heroína que dibuja Minaverry es una adolescente que va creciendo y descubriéndose en esta búsqueda, que parece nunca amasar triunfos pero se ve atravesada por la pulsión del archivo. En este sentido, Minaverry apuesta a otro tipo de personajes:

[...] la historia se fue convirtiendo en una historia de personajes que representan a alguna minoría, las protagonistas son dos chicas lesbianas: una judía y otra gitana [...]. Y todos los personajes son de una ex colonia también. Y eso yo lo siento que es como hablar de la gente que vive en las villas o en los monoblocs, los últimos orejones del tarro. ${ }^{3}$

Encontramos así, una propuesta contrapuesta a la veta política y propagandística que está presente en el género de espías tradicional, que se presenta como el paradigma y epítome del american way of life e ideal que debe ser defendido de lo otro por un héroe patriota. Estos cómics se sostienen de un solo discurso político para su fórmula narrativa, mientras que las historietas de Minaverry esgrime varias perspectivas políticas, encarnadas en sus personajes y en varios puntos del mundo, mostrando varios discursos en sus búsquedas políticas. Sin embargo, hay un personaje en el primer número que sí podemos identificar como un espía bajo los parámetros tradicionales, y ese es Tom Crane, el mercenario y ex-agente estadounidense que seduce a Lotte. Dora deduce que Crane buscó a Lotte por ser la secretaria de su objetivo ex-nazi, para acercarse lo suficiente y así envenenarlo. Esto parece confirmarse cuando el jefe de Lotte y Dora muere misteriosamente de un infarto y Crane desaparece del mapa.

Incluso la incursión de Dora como espía en conjunto con el agente del Mossad es carente de grandes aventuras, ya que no logran capturar a su objetivo y ella debe volver a Francia sin haber logrado una "cacería de nazi» exitosa. Además, no nos encontramos con ninguno de los elementos característicos que podríamos esperar cuando pensamos en espionaje; no tenemos persecuciones, bombas a segundos de explotar, ni peleas con armas. Sin embargo, Minaverry es consciente de todo este imaginario, de forma

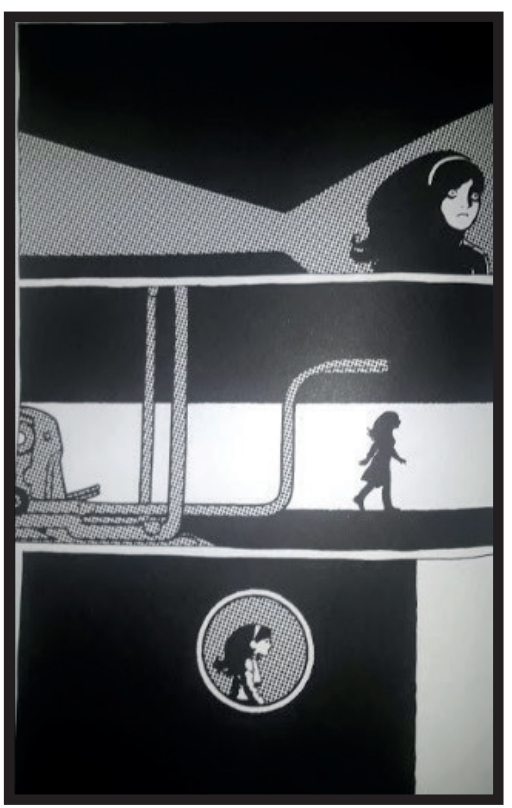

FIG. 2. Dora: malenki sukole (1963-1964) (La Maroma Ediciones, 2018), p. 34. que llega incluso a hacer una cita visual en el tercer tomo, Dora: malenki sukole (1963-

3 Acevedo, M. «Una aproximación a las geografías imaginarias en la obra de Ignacio Minaverry», en Revista de Estudios Culturales de la Universitat Jaume, vol. X (2012), p. 24. 
1964), de los créditos de uno de los espías más conocidos de la industria cultural: James Bond (FIG. 2).

También hallamos diferencias en lo que refiere a la estructura del relato, no tenemos una trama tradicional, porque no está dividida en nudo y desenlace que concluya la misión del espía. Las entregas de Dora tampoco concluyen con un cliffhanger, ni trazan ninguna conclusión totalizadora. Tenemos conclusiones de episodios, pero sin sentido de finalidad de la trama. Por ello podemos decir que entre sus rasgos principales contamos la pluralidad de los personajes que van tomando relevancia y su estructura fragmentaria. Podríamos incurrir en la discusión del porqué de este carácter fragmentario de relatos episódicos; una posible respuesta sería el formato de publicación, ya que en los primeros dos números estas tramas están divididas por pequeños títulos; estos números corresponden a los publicados inicialmente en la revista Fierro mediante entregas.

En el segundo número, Dora: El año próximo en Bobigny (1962), Dora se encuentra ante una crisis de sentido con respecto al trabajo del archivo. En ese marco recibe una carta de Beatrice Roubini, una abogada que trabaja en una organización que busca víctimas del régimen nazi para promover sus casos en la oficina central de Ludwigsburg, que se muestra interesada en su archivo y su quehacer como archivista. Roubini adivina la frustración de Dora y le explica su trabajo: «[...] hay dos maneras de cazar nazis: la divertida y la aburrida. / La divertida es secuestrarlos con un comando del Mossad... / ... y la aburrida, buscar testigos de sus crímenes para enjuiciarlos en Alemania Federal. Mi manera es la aburrida». ${ }^{4}$ Así comienza a trabajar con Roubini haciendo entrevistas, reuniendo testimonios y sumándolos al archivo. En el número siguiente, Dora: malenki sukole, hay una trama específica que se configura como el centro: Dora descubre unos documentos en el International Tracing Service que revelan que Lotte en realidad fue apropiada por la Lebensborn y luego por la familia Schmitt, y es, en realidad, Nina, de origen polaco. A su vez, en este número se incorporan los juicios a nazis que Dora ve por televisión y de los cuales obtiene más información por sus colegas. Minaverry incluye collages de fotografías de los juicios con tramas de puntos en blanco y negro que invaden las páginas, formando hilos conectores. En las páginas está la verdadera aventura de Dora: el trabajo de archivo y recorrer pasillos con cientos de cajas llenas de documentos (FIG. 3). En estos

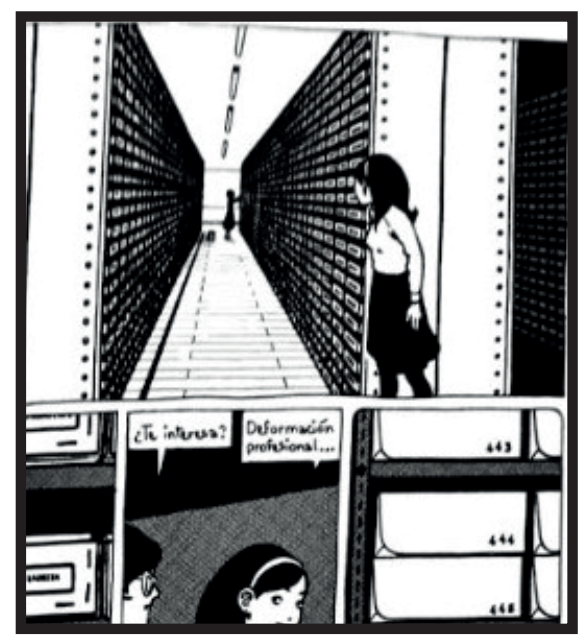

FIG. 3. Dora: malenki sukole (1963-1964). (La Maroma Ediciones, 2018), p. 25.

\footnotetext{
${ }^{4}$ Minaverry, I. Dora: el año próximo en Bobigny (1962). Buenos Aires, La Editorial Común, 2012, s.p.
} 
números se pule, por así decirlo, la labor de Dora como investigadora del archivo, más que la espía tradicional de acción.

Dora, arconte y trabajadora incansable del archivo, nos lleva a pensar en otra figura de las historietas que interrogó su pasado familiar: Art Spiegelman y Maus: A Survivor's Tale. Partimos de esta relación y marcamos la diferencia que salta de inmediato: mientras que Spiegelman se vale de flashbacks y utiliza la alegoría de la animalización en sus representaciones del pasado, Minaverry, en cambio, ancla a sus personajes en el presente y su actualización del pasado por medio del trabajo sobre el archivo. Así, como nos dice Didi-Huberman «[...] lo inimaginable requiere su propia contradicción el acto de imaginar pese a todo. Porque los nazis querían que su crimen fuera inimaginable [...]». En Dora aparece lo inimaginable del pasado representado en las historias de los diversos personajes, en los archivos y las lu-

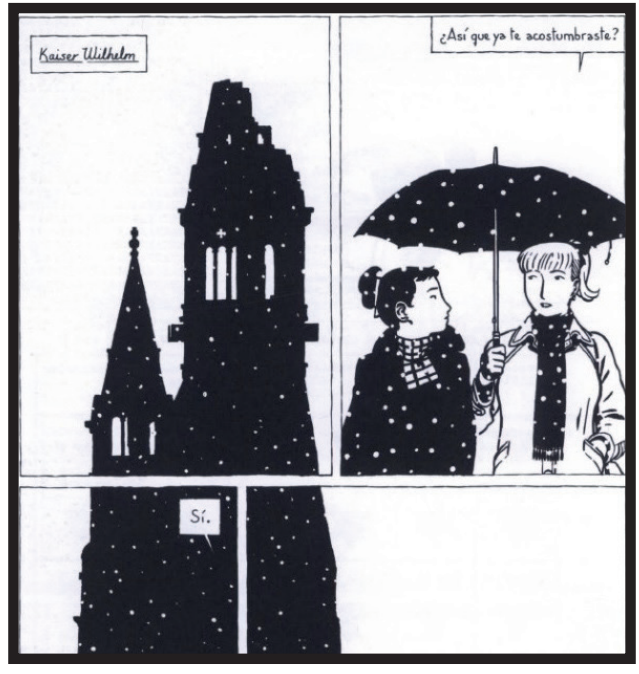

FIG. 4. Dora: Rat-line (1959-1962)

(La Editorial Común, 2009), s.p. chas que estos posibilitan, las verdades que revelan y ocultan. A esto añadimos otro nivel, en el que se establece un diálogo entre la memoria de la Shoah con la de la dictadura cívico-militar argentina entre 1976 y 1983, abriendo así vínculos transnacionales que permiten que los testimonios de hijos de desaparecidos argentinos sean utilizados para armar el relato de Lotte.

En las historias de los monoblocs, pasillos de cajas de archivos, imágenes expandidas en tramas, el pasado está presente en las búsquedas de los personajes por justicia y verdad en sus vidas cotidianas. No podemos dejar de mencionar el trabajo de investigación de Minaverry, (FIG. 4 y FIG. 5), que se permite poner en paralelo con lo que el mismo historietista define como «la obsesión de Dora con los archivos y la cuestión metódica de buscar gente, tomar testimonios, buscar datos en biblioratos, quedarse dormida sobre

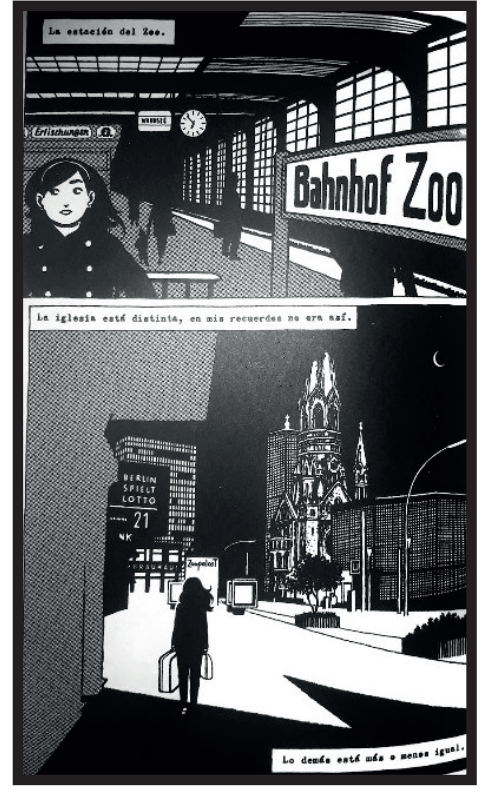

FIG. 5. Dora: malenki sukole (1963-1964) (La Maroma Ediciones, 2018), p. 40.

${ }^{5}$ Didi-Huberman, G. Imágenes pese a todo. Memoria visual del holocausto. Barcelona, Paidós, 2004, p. 100. 


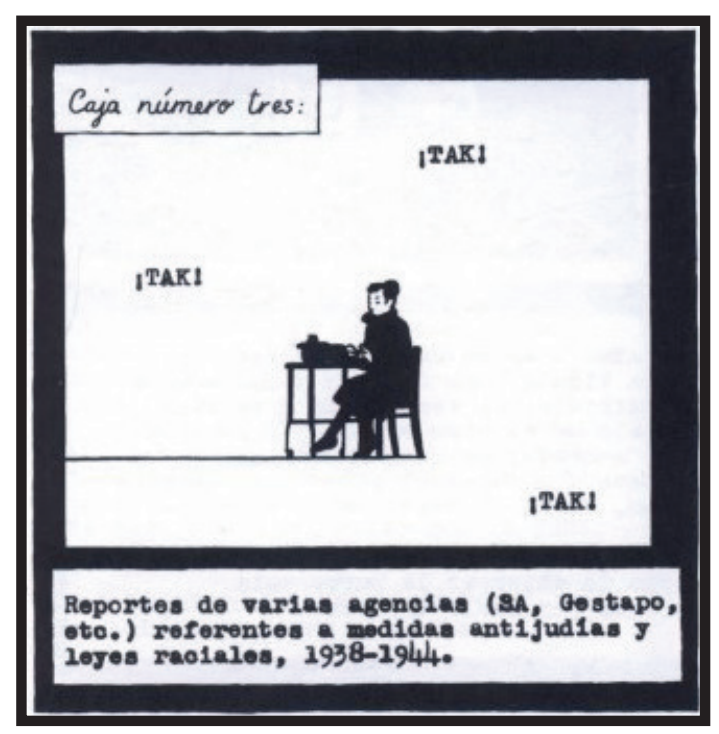

FIG. 6. Dora. Rat-line (1959-1962)

(La Editorial Común, 2009), s.p.

los archivos, toda esa cuestión siempre estuvo». Dice Graciela Goldschluk: «[...] la conciencia de su existencia [del material del archivo], su recolección y clasificación, su puesta en contexto, supone la elección del archivo como política de lectura». ${ }^{6}$ De estas reflexiones podemos servirnos para pensar la política de lectura sobre el archivo de las memorias traumáticas que nos presentan tanto Minaverry como Dora. Podemos pensar, a modo de cierre, en dos viñetas paralelas e idénticas, en una (FIG. 6), Dora aparece tecleando, y, en la segunda, Minaverry está en su mesa de dibujo, ambos hasta el tope de papeles y archivos. $^{7}$

\section{Gabriela Roxana Muñoz Cárdenas}

Gabriela R. Muñoz C. (Guayaquil, Ecuador, 1992), es estudiante de la Licenciatura y Profesorado en Letras en la Universidad Nacional de la Plata, Argentina. Actualmente se encuentra realizando su tesina de licenciatura e iniciando su investigación en comparatistica, abordando literatura, productos audiovisuales e historietas desde un enfoque transmedial.

${ }^{6}$ Goldschluk, G. «El archivo por venir, o el archivo como política de lectura», en Actas del VII Congreso Internacional Orbis Tertius, 2009. Disponible en Orbis Tertius. Revista de Teoría y Crítica Literaria https://www.orbistertius.unlp.edu.ar/

7 Tras la redacción de esta crítica el autor ha publicado el cuarto número de la serie de Dora: Amsel, Vogel, Hahn (Editorial Común, 2019). 